\title{
Genetic correlations between claw health and feet and leg conformation in Norwegian Red cows
}

\author{
C. Ødegård, ${ }^{*} \dagger^{1} M$. Svendsen, $\dagger$ and B. Heringstad ${ }^{*} \dagger$ \\ *Department of Animal and Aquacultural Sciences, Norwegian University of Life Sciences, PO Box 5003, NO-1432 Ås, Norway \\ †Geno Breeding and A. I. Association, PO Box 5003, NO-1432 Ås, Norway
}

\begin{abstract}
The aim of this study was to estimate genetic correlations between claw disorders and feet and leg conformation traits in Norwegian Red cows. A total of 188,928 cows with claw health status recorded at claw trimming from 2004 to September 2013 and 210,789 first-lactation cows with feet and leg conformation scores from 2001 to September 2013 were included in the analyses. Traits describing claw health were corkscrew claw, infectious claw disorders (dermatitis, heel horn erosion, and interdigital phlegmon), and laminitis-related claw disorders (sole ulcer, white line disorder, and hemorrhage of sole and white line). The feet and leg conformation traits were rear leg rear view (new and old definition), rear leg side view, foot angle, and hoof quality. Feet and leg conformation traits were scored linearly from 1 to 9 , with optimum scores depending on the trait. Claw disorders were defined as binary $(0 / 1)$ traits for each lactation. Threshold sire models were used to model claw disorders, whereas the feet and leg conformation traits were described by linear sire models. Three multivariate analyses were performed, each including the 5 feet and leg conformation traits and 1 of the 3 claw disorders at a time. Posterior means of heritability of liability of claw disorders ranged from 0.10 to 0.20 and heritabilities of feet and leg conformation traits ranged from 0.04 to 0.11 . Posterior standard deviation of heritability was $\leq 0.01$ for all traits. Genetic correlations between claw disorders and feet and leg conformation traits were all low or moderate, except between corkscrew claw and hoof quality $(-0.86)$, which are supposed to measure the same trait. The genetic correlations between rear leg rear view (new) and infectious claw disorders $(-0.20)$ and laminitis-related claw disorders (0.26), and between hoof quality and laminitisrelated claw disorders $(-0.33)$ were moderate. Eight of the 15 genetic correlations between claw disorders and feet and leg conformation traits had 0 included in the
\end{abstract}

Received December 16, 2013.

Accepted March 13, 2014

${ }^{1}$ Corresponding author: cecilie.odegard@nmbu.no
95\% highest posterior density interval. These results imply that selection for feet and leg conformation is not an efficient approach to genetically improve claw health in Norwegian Red cattle.

Key words: claw disorder, feet and leg conformation, genetic correlation, dairy cow

\section{INTRODUCTION}

More freestalls (Simensen et al., 2010) and a focus on claw health have increased the interest in breeding for better claw health in Norwegian Red cattle. Since 2004, claw health status at claw trimming has been reported to the Norwegian Dairy Herd Recording System, and Ødegård et al. (2013) showed that these data are suitable for genetic evaluation of Norwegian Red cattle. The current feet and leg index included in the total merit index (TMI) for Norwegian Red cattle contains 3 feet and leg conformation traits: rear leg rear view (RLRV), foot angle (FANG), and hoof quality (HQ), with weights of 35,25 , and $40 \%$, respectively. The feet and leg index receives a relative weight of $6 \%$ in the TMI (Geno, 2013). All conformation traits are scored on first-lactation cows by breeding advisors.

The number of claw health records from claw trimming has gradually increased over time, but the data are still limited (Ødegård et al., 2013). In 2012, about 60,000 Norwegian Red cows had at least 1 claw health record and about $30 \%$ of Norwegian dairy herds reported claw health. Daughter groups for claw health at first official proof of the sires are small compared with other health traits in the Norwegian Red breeding scheme, where at least 140 daughters are required. In 2012, 123 sires got their first official breeding values. These sires had, on average, 39 daughters with claw health records at the time of their first official proof. To use the new claw health information from claw trimming, claw disorders will be included in the feet and leg index. Information from genetically correlated traits could be used to increase reliability of breeding values for claw disorders.

Several authors have estimated genetic correlations between claw disorders and feet and leg conformation 
traits (e.g., Uggla et al., 2008; Häggman and Juga, 2013; van der Linde et al., 2010) and the results vary between breeds and populations. Uggla et al. (2008) estimated low to moderate genetic correlations in Swedish Red cattle, ranging from -0.31 (hock quality and heel horn erosion) to 0.17 [rear leg side view (RLSV) and heel horn erosion], whereas van der Waaij et al. (2005) estimated higher genetic correlations, ranging from -0.35 (RLRV and interdigital hyperplasia) to 0.64 (FANG and white line disorder) in Dutch dairy cattle. In Finnish Ayrshire cows, the genetic correlations between overall claw disorder and feet and leg conformation traits ranged from -0.40 (bone structure) to 0.42 (RLSV; Häggman et al., 2013), whereas Finnish Holstein cows had genetic correlations ranging from -0.51 (FANG and sole ulcer) to 0.45 (FANG and heel horn erosion; Häggman and Juga, 2013). With such a large range of estimates of genetic correlations in other breeds and populations, it is of interest to study these associations in Norwegian Red cattle. The aim of this study was to estimate genetic correlations between claw disorders and feet and leg conformation traits in Norwegian Red cattle.

\section{MATERIALS AND METHODS}

\section{Claw Health}

Claw health status, recorded at claw trimming, from 2004 to September 2013 was used in the analyses. Nine different claw disorders were recorded as healthy or diseased: corkscrew claw (CSC), dermatitis, heel horn erosion, interdigital phlegmon, sole ulcer, white line disorder, hemorrhage of sole and white line, lameness, and acute trauma. All trimmed cows were recorded, including healthy cows. A cow could have more than 1 claw disorder recorded on the same day. Also, the identification of claw trimmer and date of claw trimming were recorded at each claw trimming. The recording is voluntary and therefore not reported by all herds. Approximately $30 \%$ of the cows in a herd had claw health recorded and about $18 \%$ of the cows had more than 1 claw health record during a lactation (Ødegård et al., 2013). More details of claw health data in Norway can be found in Ødegård et al. (2013).

Based on results from Ødegård et al. (2013), 1 single claw disorder (CSC) and 2 groups of claw disorders [infectious (INF) and laminitis-related (LAM) claw disorders] were included in the analyses (Table 1). The INF claw disorders included dermatitis, heel horn erosion, and interdigital phlegmon; and LAM claw disorders included sole ulcer, white line disorder, and hemorrhage of sole and white line. Claw health data was edited as described in Ødegård et al. (2013); only cows and lactations with claw health records, daughters of Norwegian Red AI sires, and herds recording more than $10 \%$ or at least 10 cows with normal claws were included. In addition, age at calving should be between 16 and 48 mo for first lactation, 26 and 61 mo for second lactation, 36 and 74 mo for third lactation, and 45 and 87 mo for fourth lactation. After editing, the total number of claw health records was 285,581 from 188,928 cows in 6,891 herds and 2,101 sires had daughters with claw health data in the final data set. A cow was defined as either healthy (0) or diseased (1) for each of the 3 traits (CSC and INF and LAM claw disorders) in each lactation where at least 1 clawtrimming record was present. If a cow had more than 1 case of a claw disorder during a lactation, only the first observation was included in the analyses. Few cows had claw health records for more than 1 lactation and, therefore, a possible permanent environment effect was ignored in the analyses. The mean frequency of CSC and INF and LAM claw disorders was 0.11, 0.06 and 0.07 , respectively (Table 1 ).

\section{Feet and Leg Conformation}

Feet and leg conformation scores from 1987 to 2013 were available, but only data from 2001 to September 2013 were used in the analyses, due to changes in the scoring system in 2001. Breeding advisors score feet and leg conformation together with other conformation traits on first-lactation cows. Four feet and leg conformation traits are recorded: RLRV, RLSV, FANG, and HQ (Table 1). The definition of RLRV changed in 2010 and was, therefore, treated as 2 correlated traits: new ( RLRV_N) and old (RLRV_O). Hoof quality from conformation scoring and CSC from claw trimming measures the same trait, but are recorded differently (Table 1). Hoof quality is scored when the cow is standing, whereas CSC is measured when the cow is fixed and the sole is inspected. The feet and leg conformation traits are scored on a scale from 1 to 9 , with the optimum value depending on the trait (Table 1). Data editing for feet and leg conformation traits was performed as in routine genetic evaluation (Interbull, 2011): only daughters of Norwegian Red AI sires with age at first calving between 18 and 33 mo, and time for conformation scoring within defined intervals (months after calving) were included. The final data set had feet and leg conformation scores for 210,789 first-lactation cows in 13,659 herds and by 1,655 sires. The number of records for all trait combinations of claw health and feet and leg conformation are presented in Table 2.

The total number of sires with daughter information on claw health, feet and leg conformation, or both was 


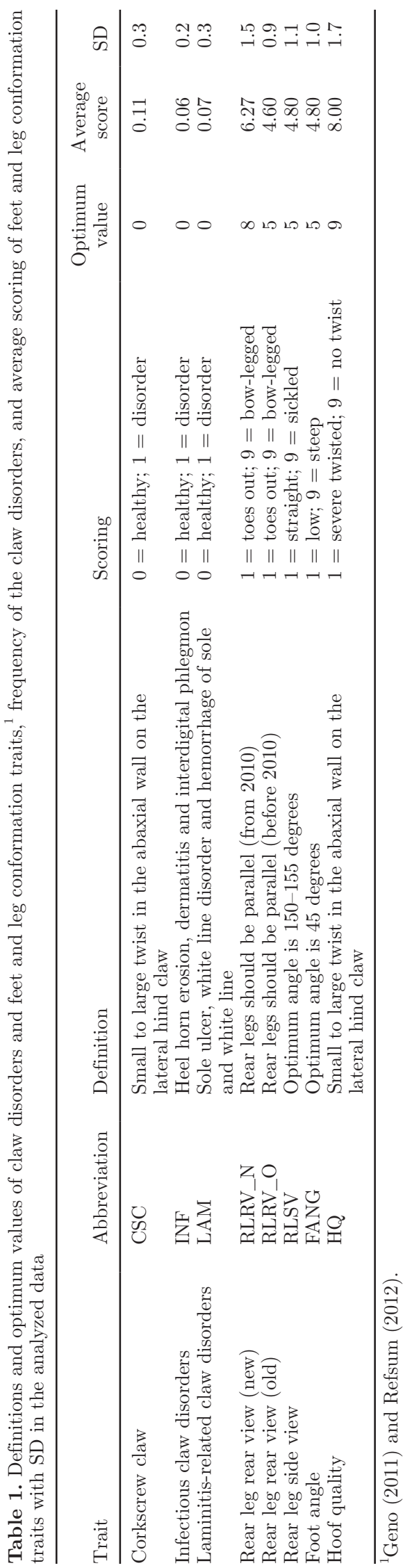

2,145 . Of these sires, 1,611 had daughter information on both trait groups. The pedigree of sires with daughters was traced back as far as possible and the final pedigree file contained 18,895 animals.

\section{Statistical Model}

A Bayesian approach using Gibbs sampling was applied. The 3 claw disorders (CSC and INF and LAM claw disorders) were defined as binary traits and analyzed with threshold models, whereas the 5 feet and leg conformation traits (RLRV_N, RLRV_O, RLSV, FANG, and HQ) were assumed to be normally distributed and analyzed with linear models.

The threshold sire model used for claw disorders was as described in Ødegård et al. (2013):

$$
\boldsymbol{\lambda}=\mathbf{X} \boldsymbol{\beta}+\mathbf{Z}_{\mathbf{h}} \mathbf{h}+\mathbf{Z}_{\mathbf{s}} \mathbf{s}+\mathbf{e},
$$

where $\boldsymbol{\lambda}$ is a vector of unobserved liabilities of the trait; $\boldsymbol{\beta}$ is a vector of systematic effects, including lactation number, calving year and month, time for claw trimming (months after calving), and claw trimmer; $\mathbf{h}$ is a vector of herd effects, with 6,891 levels; $\mathbf{s}$ is a vector of sire effects; $\mathbf{X}, \mathbf{Z}_{\mathrm{h}}$, and $\mathbf{Z}_{\mathrm{s}}$ are the corresponding incidence matrices; and $\mathbf{e}$ is a vector of residuals. Lactation number had 4 levels, where the fourth class included lactation 4 to 13; calving year and month had 114 levels; time for claw trimming (months after calving) had 12 levels; and claw trimmer was divided into 4 groups: certified claw trimmers, other claw trimmers, farmers, and others (e.g., veterinarian).

The linear sire model for feet and leg conformation traits included the same effects as the linear animal model used in routine genetic evaluation for Norwegian Red cattle (Interbull, 2011):

$$
\mathbf{y}=\mathbf{X} \boldsymbol{\beta}+\mathbf{Z}_{\mathrm{hy}} \mathbf{h y}+\mathbf{Z}_{\mathrm{s}} \mathbf{s}+\mathbf{e},
$$

where $\mathbf{y}$ is a vector of observations of the trait; $\boldsymbol{\beta}$ is a vector of systematic effects, including year and month of calving, time from calving (months) and time from milking (hours) to scoring, and age at scoring (in months); hy is a vector of herd-year effects; $\mathbf{s}$ is a vector of sire effects; $\mathbf{X}, \mathbf{Z}_{\mathrm{hy}}$, and $\mathbf{Z}_{\mathrm{s}}$ are the corresponding incidence matrices; and $\mathbf{e}$ is a vector of residuals. Year and month of calving had 46 levels for RLRV_N, 116 for RLRV_O, and 151 levels for RLSV, FANG, and HQ; time from calving (months) and time from milking (hours) to scoring had 96 levels for all traits; age (in months) at scoring had 7 levels for all traits; and number of herd-year classes were 10,395 for RLVR_N, 50,199 for RVLR_O, and 60,594 for RLSV, FANG, and HQ. Classifier (breeding advisor) was not included in 
Table 2. Number of records for trait combinations of corkscrew claw (CSC); infectious claw disorders (INF); laminitis-related claw disorders (LAM); rear leg rear view, new (RLRV_N); rear leg rear view, old (RLRV_O); rear leg side view (RLSV); foot angle (FANG); and hoof quality (HQ)

\begin{tabular}{lrrrrrrrr}
\hline Trait & \multicolumn{1}{c}{ CSC } & \multicolumn{1}{c}{ INF } & LAM & RLRV_N & RLRV_O & RLSV & FANG & HQ \\
\hline CSC & 285,581 & & & & & & & \\
INF & 285,581 & 285,581 & & & & & & \\
LAM & 285,581 & 285,581 & 285,581 & & & & & \\
RLRV_N & 11,850 & 11,850 & 11,850 & 47,474 & & & & \\
RLRV_O & 14,888 & 14,888 & 14,888 & 0 & 163,315 & & & \\
RLSV & 26,738 & 26,738 & 26,738 & 47,474 & 163,315 & 210,789 & & \\
FANG & 26,738 & 26,738 & 26,738 & 47,474 & 163,315 & 210,789 & 210,789 & \\
HQ & 26,738 & 26,738 & 26,738 & 47,474 & 163,315 & 210,789 & 210,789 & 210,789 \\
\hline
\end{tabular}

the model because this effect is confounded with the herd-year effect.

Because of computational time, the 5 feet and leg conformation traits were analyzed together with 1 of the 3 claw disorders at a time. It was assumed that $\operatorname{var}(\mathbf{h}) \sim N\left(0, \sigma_{h}^{2}\right), \operatorname{var}(\mathbf{h y})=\mathbf{H Y} \otimes \mathbf{I}, \operatorname{var}(\mathbf{s})=\mathbf{G} \otimes \mathbf{A}$, and $\operatorname{var}(\mathbf{e})=\mathbf{R} \otimes \mathbf{I}$, where $\sigma_{h}^{2}$ is the herd variance for claw disorders, $\mathbf{H Y}$ is the $5 \times 5$ matrix containing herd-year variances among the 5 feet and leg conformation traits, herd-year covariances were assumed to be 0 among these traits (same as in the routine evaluation), $\mathbf{I}$ is the identity matrix, $\mathbf{A}$ is the additive genetic relationship matrix, and $\mathbf{G}$ and $\mathbf{R}$ are the $6 \times 6$ genetic and residual (co)variance matrices, respectively, for the 5 feet and leg conformation traits and 1 of the 3 claw disorders. For the binary claw disorders, the residual variance was assumed to be 1 . Residual covariance was assumed to be 0 between RLRV_N and RLRV_O, because no cows had observation for both new and old RLRV, and between claw disorders and the 5 feet and leg conformation traits. These assumptions reduced computational time without affecting the results.

To analyze the data, the RJMC procedure in DMU software (Madsen and Jensen, 2010) was used. The Raftery and Lewis method in BOA software (Smith, 2005) was used for convergence diagnostics. The length of burn-in was set to 10,000 iterations for all 3 models. The total number of iterations, after burn-in, was 200,000 for the models including CSC and INF claw disorders and 350,000 for the model including LAM claw disorders.

Heritability $\left(h^{2}\right)$ was calculated using

$$
h^{2}=\frac{4 \times \sigma_{s}^{2}}{\sigma_{s}^{2}+\sigma_{e}^{2}},
$$

where $\sigma_{s}^{2}$ is the sire variance and $\sigma_{e}^{2}$ is the residual variance.

\section{RESULTS AND DISCUSSION}

\section{Heritabilities}

Posterior means of heritability of liability of CSC and INF and LAM claw disorders was 0.20, 0.12, and 0.10, respectively (Table 3 ), which corresponds well with those of Ødegård et al. (2013). Estimated heritabilities were also in accordance with other studies (e.g., van der Waaij et al., 2005; Swalve et al., 2008; Buch et al., 2011). van der Spek et al. (2013) found that the underlying heritability of some claw disorders changed when including herds where at least $70 \%$ of the cows were trimmed compared with herds were less than $35 \%$ of the cows were trimmed. At present, our editing criteria were less strict due to limited data. The heritability estimates may, therefore, be affected and higher heritabilities may be obtained with more complete data in the future. The heritabilities for the 5 feet and leg conformation traits ranged from 0.04 (HQ) to 0.11 (RLSV), with small standard deviations $(\leq 0.01$; Table 3$)$, and were in accordance with heritabilities used in routine genetic evaluations for these traits in Norwegian Red cattle (Geno, 2013). Heritabilities of RLRV_N, RLSV, and FANG were lower $(0.09-0.11)$ in this study than estimates by Laursen et al. (2009), Uggla et al. (2008), and van der Waaij et al. (2005). However, heritabilities of RLRV_N and FANG were in accordance with those of Häggman et al. (2013).

\section{Herd Variance}

The herd variance for CSC and INF and LAM claw disorders was $0.55,1.15$, and 0.36 , respectively (Table $3)$. For the feet and leg conformation traits, the herdyear variance varied between 0.08 (RLRV_O) and 0.89 (HQ; Table 3). The models did not include a permanent environment effect for claw disorders, meaning that the herd effect could possibly include a permanent effect of the cow. 
Table 3. Posterior mean and SD of heritability, sire variance $\left(\sigma_{\mathrm{s}}^{2}\right)$, and herd variance $\left(\sigma_{h}^{2}\right)$ of claw disorders and feet and leg conformation traits

\begin{tabular}{|c|c|c|c|c|c|c|}
\hline \multirow[b]{2}{*}{ Trait } & \multicolumn{2}{|c|}{ Heritability $^{1}$} & \multicolumn{2}{|c|}{$\sigma_{e}^{2}$} & \multicolumn{2}{|c|}{$\sigma_{h}^{2}$} \\
\hline & Mean & $\mathrm{SD}$ & Mean & $\mathrm{SD}$ & Mean & $\mathrm{SD}$ \\
\hline Corkscrew claw & 0.20 & 0.01 & 0.05 & $<0.01$ & 0.55 & 0.02 \\
\hline Infectious claw disorders & 0.12 & 0.01 & 0.03 & $<0.01$ & 1.15 & 0.04 \\
\hline Laminitis related claw disorders & 0.10 & 0.01 & 0.02 & $<0.01$ & 0.36 & 0.01 \\
\hline Rear leg rear view (new) & 0.09 & 0.01 & 0.03 & $<0.01$ & 0.54 & 0.01 \\
\hline Rear leg rear view (old) & 0.07 & $<0.01$ & 0.01 & $<0.01$ & 0.08 & $<0.01$ \\
\hline Rear leg side view & 0.11 & 0.01 & 0.03 & $<0.01$ & 0.13 & $<0.01$ \\
\hline Foot angle & 0.10 & 0.01 & 0.02 & $<0.01$ & 0.15 & $<0.01$ \\
\hline Hoof quality & 0.04 & $<0.01$ & 0.02 & $<0.01$ & 0.89 & 0.01 \\
\hline
\end{tabular}

\section{Genetic Correlations}

The posterior distributions of the genetic correlations between claw disorders and feet and leg conformation traits were, in general, symmetric (Figure 1), with standard deviations varying between 0.03 and 0.08 (Table 4). Figure 1 show that many of the distributions overlap and have means close to 0 . The strongest genetic correlation $(-0.86)$ was found between CSC and HQ (Table 4 ), with the $95 \%$ highest posterior density interval ranging from -0.92 to -0.79 . The high genetic correlation was expected because CSC and $\mathrm{HQ}$ are supposed to measure the same trait. The genetic correlation has a negative sign because of opposite scaling (Table 1) and indicates a favorable genetic correlation. The result shows that CSC can replace HQ in the feet and leg index, which is preferable because CSC is expected to be a more accurate measure of the trait. However, the high genetic correlation indicates that $\mathrm{HQ}$ can be used as an indicator trait for CSC. The genetic correlation between RLRV_N and INF $(-0.20)$ and LAM (0.26) claw disorders, respectively, were moderate and in opposite directions, meaning that bowed legs are associated with more INF claw disorders and toes out are associated with more LAM claw disorders. The genetic correlation of -0.33 between HQ and LAM claw disorders is favorable in the sense that selection for better $\mathrm{HQ}$ will reduce LAM claw disorders. Between RLRV_O and INF and LAM claw disorders, respectively, the genetic correlations were not significantly different from 0 . Foot angle had genetic correlations that were low but significantly different from 0 to LAM (0.17) and INF (0.16) claw disorders. The genetic correlations between claw disorders and feet and leg conformation traits were, in general, low and the $95 \%$ highest posterior density included 0 for 8 out of 15 correlations (Table 4). Despite relatively few cows with information on both claw health and feet and leg conformation (Table 2), the estimated genetic correlations were relatively precise (Table 4 and Figure 1).
Uggla et al. (2008) showed that dermatitis and heel horn erosion, which are INF claw disorders, and sole hemorrhage and sole ulcer, which are LAM claw disorders, had genetic correlation to RLSV that differed significantly from 0 in Swedish Red cattle. However, they found no significant genetic correlation between the mentioned claw disorders and RLRV. Also, van der Linde et al. (2010) found significant genetic correlation between RLSV and sole ulcer (0.41) for first-lactation cows. These results differ from the present study, where no significant genetic correlations between RLSV and INF or LAM claw disorders were found, whereas moderate genetic correlations were found between RLRV_N and both INF and LAM claw disorders. Häggman and Juga (2013) estimated negative correlation between RLRV and heel horn erosion $(-0.29)$ and a significant positive genetic correlation between FANG and heel horn erosion (0.45), whereas most other genetic correlations were not significantly different from 0 . van der Waaij et al. (2005) found high genetic correlation between FANG and white line disorder (0.64), whereas in the present study, FANG and LAM claw disorders (which include white line disorder) had low genetic correlation (0.17). The different result could be due to a low genetic correlation between FANG and the other traits included in LAM claw disorders. Moderate genetic correlation between RLRV and digital dermatitis $(-0.32)$ and interdigital dermatitis $(-0.23)$ for firstlactation cows was found by van der Linde et al. (2010), which was in agreement with the genetic correlation found between RLRV_N and INF claw disorders in the current study $(-0.20)$.

Rear leg side view is not included in the current TMI in Norway, and results from the present study show that claw disorders will not gain additional information from RLSV (Table 4). This was in contrast to a study by Häggman et al. (2013), who estimated moderate genetic correlation between RLSV and overall claw health (0.42) in Finnish Ayrshire cattle and suggested to use 

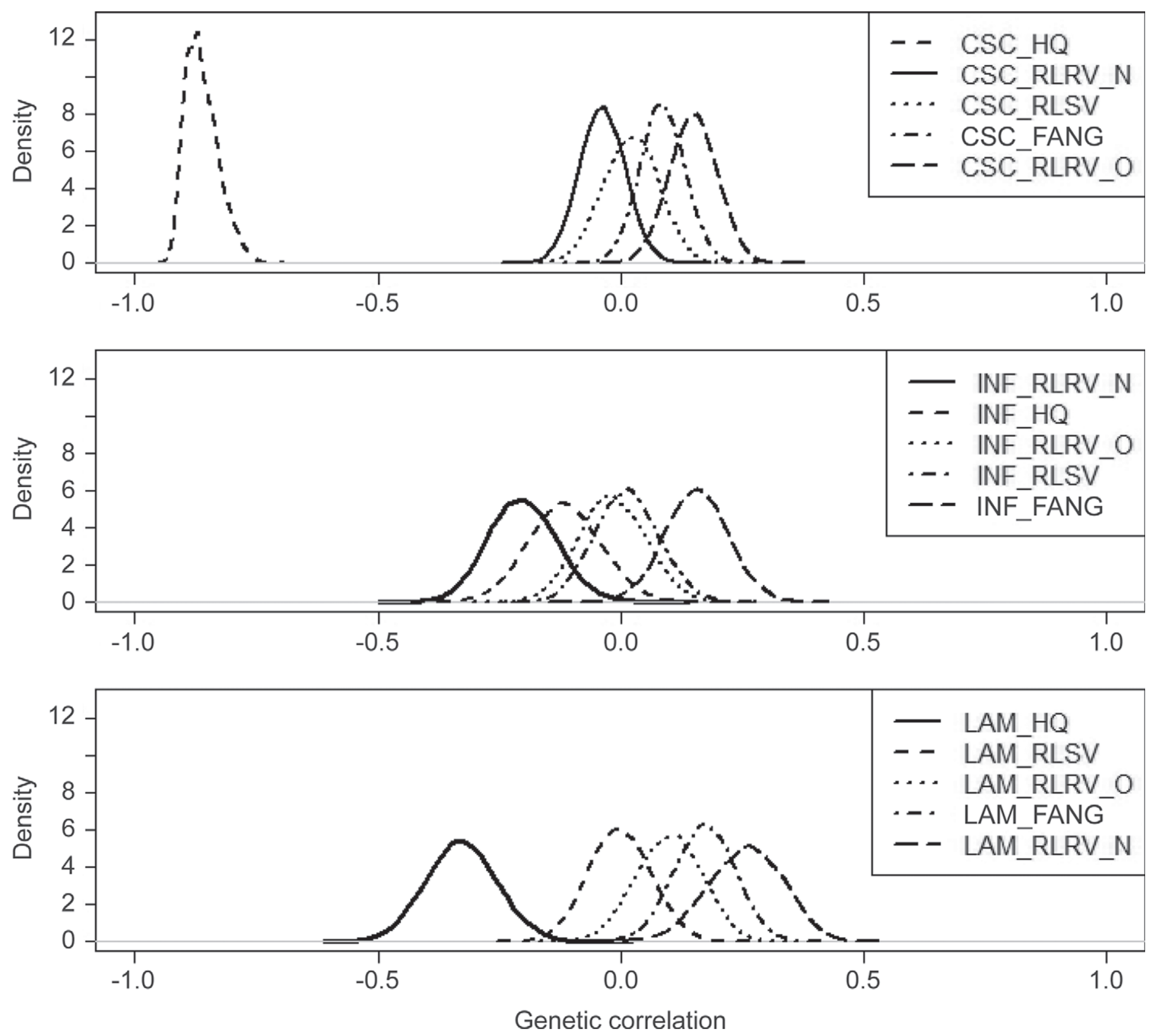

Figure 1. Posterior distribution of genetic correlations between claw disorders [corkscrew claw (CSC), infectious (INF) claw disorders, and laminitis-related (LAM) claw disorders] and feet and leg conformation traits [rear leg rear view, new (RLRV_N); rear leg rear view, old (RLRV_O); rear leg side view (RLSV); foot angle (FANG); and hoof quality (HQ)].

it as indicator trait for claw disorders. Gernand et al. (2013) estimated favorable genetic correlations between claw disorder and RLSV and FANG. The contradicting results found between different studies could be due to differences in trait definitions and frequency of claw disorders between breeds and populations. Battagin et al. (2012) investigated the genetic correlation of the trait overall feet and leg conformation among different countries and found a correlation of 0.68 across countries. Another study by Battagin et al. (2013) estimated changes in genetic correlation of overall feet and leg conformation over time and concluded that further harmonization of the traits is needed to obtain better genetic correlations across countries. In the Nordic countries, harmonization of conformation traits and claw disorders will be implemented, and this will provide a better comparison of these traits between the Nordic breeds.

Although the results indicate that selection for feet and leg conformation traits is not an efficient approach 
Table 4. Genetic correlations between claw disorders and feet and leg conformation traits (posterior means, with SD in parentheses and 95\% highest posterior density intervals in brackets)

\begin{tabular}{|c|c|c|c|c|c|}
\hline \multirow[b]{2}{*}{ Claw disorder } & \multicolumn{5}{|c|}{ Conformation trait } \\
\hline & $\begin{array}{c}\text { Rear leg rear } \\
\text { view new }\end{array}$ & $\begin{array}{c}\text { Rear leg rear } \\
\text { view old }\end{array}$ & $\begin{array}{c}\text { Rear leg } \\
\text { side view }\end{array}$ & $\begin{array}{l}\text { Foot } \\
\text { angle }\end{array}$ & $\begin{array}{c}\text { Hoof } \\
\text { quality }\end{array}$ \\
\hline \multirow[t]{2}{*}{ Corkscrew claw } & $0.02(0.06)$ & $0.15(0.05)$ & $-0.04(0.05)$ & $0.09(0.05)$ & $-0.86(0.03)$ \\
\hline & {$[-0.09 ; 0.13]$} & {$[0.05 ; 0.25]$} & {$[-0.13 ; 0.05]$} & {$[-0.01 ; 0.18]$} & {$[-0.92 ;-0.79]$} \\
\hline \multirow[t]{2}{*}{ Infectious claw disorders } & $-0.20(0.07)$ & $-0.02(0.07)$ & $0.01(0.07)$ & $0.16(0.07)$ & $-0.12(0.08)$ \\
\hline & {$[-0.33 ;-0.05]$} & {$[-0.15 ; 0.12]$} & {$[-0.11 ; 0.14]$} & {$[0.03 ; 0.29]$} & {$[-0.26 ; 0.04]$} \\
\hline \multirow[t]{2}{*}{ Laminitis-related claw disorders } & $0.26(0.08)$ & $0.10(0.07)$ & $0.00(0.07)$ & $0.17(0.06)$ & $-0.33(0.07)$ \\
\hline & {$[0.11 ; 0.41]$} & {$[-0.03 ; 0.23]$} & {$[-0.13 ; 0.13]$} & {$[0.05 ; 0.30]$} & {$[-0.47 ;-0.18]$} \\
\hline
\end{tabular}

to genetically improve claw health, feet and leg conformation traits may be of value to other health and welfare aspects of the cow.

Other possible indicator traits for claw health are locomotion and lameness (e.g., van der Waaij et al., 2005; Laursen et al., 2009; Weber et al., 2013). van der Waaij et al. (2005) concluded that locomotion was useful for predicting claw disorders later in life, but more investigation was needed. Several authors concluded that direct selection against claw disorders is the most efficient way to improve claw health (e.g., Laursen et al., 2009; Häggman et al., 2013; Weber et al., 2013). Gernand et al. (2013) discussed selection strategies for claw health, comparing direct and indirect selection, and concluded that including direct claw health in the ultimate breeding goal was the most promising alternative. In Norwegian Red cattle, locomotion and lameness are not recorded routinely, and direct selection against claw disorders would be the best choice for genetic improvement of claw health.

\section{CONCLUSIONS}

Genetic correlations between claw disorders and feet and leg conformation traits were, in general, low and selection for feet and leg conformation is, therefore, not an efficient approach for genetic improvement of claw health in Norwegian Red cattle. The exception was $\mathrm{HQ}$, which, with a genetic correlation of -0.86 to CSC, is a useful indicator trait that can provide additional information to CSC.

\section{ACKNOWLEDGMENTS}

The authors thank the Norwegian Dairy Herd Recording System and the Norwegian Cattle Health Service (Ås, Norway) for access to data, the Norwegian Research Council (Oslo, Norway) and Geno SA (Hamar, Norway) for funding, and Erling Sehested (Geno SA) for help in interpreting the feet and leg conformation traits.

\section{REFERENCES}

Battagin, M., F. Forabosco, J. H. Jakobsen, M. Penasa, T. J. Lawlor, and M. Cassandro. 2012. International genetic evaluation of Holstein bulls for overall type traits and body condition score. J. Dairy Sci. 95:4721-4731.

Battagin, M., F. Forabosco, M. Penasa, and M. Cassandro. 2013. Cluster analysis on across-country genetic correlations for overall type traits and body condition score of Holstein bulls. Livest. Sci. 151:108-114.

Buch, L. H., A. C. Sørensen, J. Lassen, P. Berg, J.-Å. Eriksson, J. H. Jakobsen, and M. K. Sørensen. 2011. Hygiene-related and feedrelated hoof diseases show different patterns of genetic correlations to clinical mastitis and female fertility. J. Dairy Sci. 94:1540-1551.

Geno. 2011. Eksteriør hos NRF-kyr. Beskrivelse av eksteriørvurderingene. Revised June 2011. Geno, Hamar, Norway.

Geno. 2013. Avl for bedre bein. Accessed Nov. 27, 2013. http://www. geno.no/Forsiden/NRF/Egenskapene-i-avlsarbeidet/Bein/.

Gernand, E., D. A. Döhne, and S. König. 2013. Genetic background of claw disorders in the course of lactation and their relationship with type traits. J. Anim. Breed. Genet. 130:435-444.

Häggman, J., and J. Juga. 2013. Genetic parameters for hoof disorders and feet and leg conformation traits in Finnish Holstein cows. J. Dairy Sci. 96:3319-3325.

Häggman, J., J. Juga, M. J. Sillanpää, and R. Thompson. 2013. Genetic parameters for claw health and feet and leg conformation traits in Finnish Ayrshire cows. J. Anim. Breed. Genet. 130:89-97.

Interbull. 2011. National genetic evaluation forms provided by countries. Accessed Apr. 4, 2014. https://wiki.interbull.org/public/ Nat_GE_Forms?action=print.

Laursen, M. V., D. Boelling, and T. Mark. 2009. Genetic parameters for claw and leg health, foot and leg conformation, and locomotion in Danish Holstein. J. Dairy Sci. 92:1770-1777.

Madsen, P., and J. Jensen. 2010. An user's guide to DMU. A package for analysing multivariate mixed models. Version 6 , release 5.0. University of Aarhus, Faculty of Agricultural Sciences, Dept. of Genetics and Biotechnology, Research Centre Foulum, Tjele, Denmark.

Ødegård, C., M. Svendsen, and B. Heringstad. 2013. Genetic analyses of claw health in Norwegian Red cows. J. Dairy Sci. 96:7274-7283.

Refsum, T. 2012. Referansekodeverket for husdyrsjukdommer i Norge. Animalia, Helsetjeneseten for storfe, Helsetjenesten for geit and Koorimp. Accessed Sep. 30, 2013. http://www.animalia.no/ upload/FIler\%20til\%20nedlasting/HT-Fjørfe/25.09.2012\%20-\%20 Referansekodeverk\%20for\%20husdyrsjukdommer\%20i\%20Norge. pdf.

Simensen, E., O. Østerås, K. E. Bøe, C. Kielland, L. E. Ruud, and G. Næss. 2010. Housing system and herd size interactions in Norwegian Dairy herds; associations with performance and disease incidence. Acta Vet. Scand. 52:14.

Smith, B. J. 2005. Bayesian Output Analyses Program (BOA) Version 1.1 User's Manual. Accessed May 2, 2013. http://www.publichealth.uiowa.edu/boa/BOA.pdf.

Swalve, H. H., H. Alkhoder, and R. Pijl. 2008. Estimates for breeding values for sires based on diagnoses recorded at hoof trimming: 
Relationship with EBV for conformation traits. Interbull Bull. 38:87-90.

Uggla, E., J. H. Jakobsen, C. Bergsten, J.-Å. Eriksson, and E. Strandberg. 2008. Genetic correlation between claw health and feet and leg conformation traits in Swedish dairy cows. Interbull Bull. 38:91-95.

van der Linde, C., G. de Jong, E. P. C. Koenen, and H. Eding. 2010. Claw health index for Dutch dairy cattle based on claw trimming and conformation data. J. Dairy Sci. 93:4883-4891.

van der Spek, D., J. A. M. van Arendonk, A. A. A. Vallée, and H. Bovenhuis. 2013. Genetic parameters for claw disorders and the effect of preselecting cows for trimming. J. Dairy Sci. 96:6070-6078. van der Waaij, E. H., M. Holzhauer, E. Ellen, C. Kamphuis, and G. de Jong. 2005. Genetic parameters for claw disorders in Dutch dairy cattle and correlations with conformation traits. J. Dairy Sci. 88:3672-3678

Weber, A., E. Stamer, W. Junge, and G. Thaller. 2013. Genetic parameters for lameness and claw and leg diseases in dairy cows. J. Dairy Sci. 96:3310-3318. 